УДК 582.711.711:577.13

\title{
ФЛАВОНОИДЫ НЕКОТОРЫХ ВИДОВ РОДА RHODODENDRON L. ФЛОРЫ СИБИРИ И ДАЛЬНЕГО ВОСТОКА
}

\author{
(C) Е.А. Карпова", А.В. Каракулов
}

\author{
Центральный сибирский ботанический сад СО РАН, ул. Золотодолинская, \\ 101, Новосибирск, 630090 (Россия), e-mail: vysochina_galina@mail.ru
}

Методом ВЭЖХ изучен состав и содержание агликонов и гликозидов флавоноидов в листьях Rhododendron adamsii, Rh. parvifolium, Rh. impeditum, а также близкородственных видов из подсекции Rhodorastra (Rh. dauricum, Rh. ledebourii, Rh. sichotense, Rh. mисronulatum) из популяций Якутии, Тывы, Амурской области, Алтая, Приморского края, Бурятии, Китая. Содержание агликонов в гидролизатах большинства исследованных видов составляет около $1 \%$, в их составе преобладают кверцетин и дигидрокверцетин. У видов Rh. adamsii и Rh. parvifolium агликоны обнаружены преимущественно в свободном состоянии, а у видов подсекции Rhodorastra - в связанном. Степень парного сходства исследованных видов по составу фенольных соединений экстрактов и гидролизатов варьирует в пределах от 30 до $90 \%$, максимальная - в парах видов Rh. sichotense-Rh. dauricum, Rh. adamsii-Rh. ledebourii. Анализ сходства состава флавоноидов исследованных видов рода не показал соответствия анатомо-морфологической классификации Д. Чемберлена. Выявлена значительная степень родства видов Rh. adamsii и Rh. parvifolium. Минимальная степень группового сходства по составу флавоноидов экстрактов и гидролизатов Rh. impeditum ставит под сомнение его положение, наряду с Rh. parvifolium, в подсекции Lapponica.

Ключевые слова: Rhododendron, флавоноиды, флавонолы, кверцетин, кемпферол, мирицетин, дигидрокверцетин.

\section{Введение}

Биологическая активность представителей рода Rhododendron L. с выраженными диуретическими, противовоспалительными и антимикробными свойствами $[1,2]$ во многом обусловлена наличием арбутина, производных бензойной и коричной кислот, кумаринов и флавоноидов [3, 4].

Основными флавоноидными компонентами рододендронов являются флавонолы - кверцетин, кемпферол, мирицетин и их гликозиды, 5-метиловые и 3,5-диметиловые эфиры; 8-гидроксифлавонол - госсипетин; флавононолы (дигидрокверцетин, дигидрокемпферол, дигидромирицетин) и их гликозиды [3-8].

На территории России произрастает 16 видов рододендронов, основная часть которых (13 видов) встречается только во флоре Сибири и Дальнего Востока [9, с. 41-50]. Систематика рода Rhododendron сложна и еще недостаточно разработана. Российские исследователи классифицируют род Rhododendron несколько иначе, чем зарубежные. В настоящий момент отсутствует единая общепринятая классификационная схема таксона, что объясняется значительным объемом рода (более 800 видов) и наличием у его представителей большого количества конвергентных морфологических признаков, усложняющих построение естественной классификации.

Система рода, разработанная российскими учеными, подразделяет род Rhododendron на подроды и

Карпова Евгения Алексеевна - старший научный сотрудник лаборатории фитохимии, кандидат биологических наук, тел.: (383) 334-44-68, e-mail: karpova@csbg.nsc.ru

Каракулов Анатолий Владимирович - научный сотрудник, кандидат биологических наук, e-mail: krk@inbox.ru ряды. В ней Rh. adamsii Rehd. и Rh. parvifolium Adams отнесены к подроду Osmothamnus Maxim. (ряд Fragrantia E. Busch и ряд Parvifolia E. Busch соответственно). Виды Rh. dauricum L., Rh. ledebourii Pojark., Rh. sichotense Pojark. и Rh. mucronulatum Turcz. составляют ряд Daurica Poiark подрода Rhodorastrum (Maxim.) Drude [10, c. 22-93].

\footnotetext{
* Автор, с которым следует вести переписку.
} 
В соответствии с альтернативной системой рода, которой придерживаются западноевропейские и китайские исследователи $[11,12]$, виды флоры Китая Rh. impeditum Balf. et Smith и Rh. parvifolium отнесены к подсекции Lapponica (Hutchinson) Sleumer секции Rhododendron. К этой же секции относятся и четыре вида: Rh. dauricum, Rh. ledebourii, Rh. sichotense и Rh. mucronulatum (подсекция Rhodorastra (Maximowicz) Cullen, a $R$. adamsii здесь отнесен к секции Pogonanthum G. Don.

Реконструкция системы рода на основе ITS1-ITS2-последовательностей ДНК [13] показала в целом соответствие анатомо-морфологической классификации Д. Чемберлена. При этом была обнаружена тесная степень родства видов Rh. adamsii и Rh. parvifolium, что поставило под сомнение выделение их в разные секции. В подсекции Rhodorastra секции Rhododendron подрода Rhododendron была выявлена низкая степень дифференциации видов Rh. mисronulatum, Rh. dauricum, Rh. ledebourii и Rh. sichotense, что указывает на их недавнее обособление.

Таким образом, очевидно, что действующая система анатомо-морфологических и биохимических признаков недостаточна для окончательного уточнения степени родства видов. Включение флавоноидов в систему признаков для реконструкции системы рода является достаточно актуальным.

В надземной части рододендронов подсекции Rhodorastra были найдены кверцетин, мирицетин и гликозиды кверцетина - гиперозид и авикулярин $[4,7,8]$. В соцветиях $R$. тисronulatum обнаружен также азалеатин (5-метилкверцетин) [6], в листьях $R$. dauricum - азалеатин [4], 5-метилкемпферол и 5-метилмирицетин [14]. В побегах и цветках $R$. тисronulatum найдены также кверцитрин, гликозиды кемпферола - астрагалин и афзелин, гликозид мирицетина мирицитрин, дигидрокверцетин и его арабинозид, дигидромирицетин (ампелопсин) $[15,16]$. В листьях растений Rh. dauricum выявлен также флаванон фаррерол [17].

В надземной части Rh. adamsii обнаружены кверцетин, кемпферол, нарингенин, рутин, гиперозид [18], а также мирицетин и дигидрокверцетин [19].

Состав флавоноидов видов подсекции Lapponica слабо изучен. J.B. Harborne и A. Williams [3] обнаружили в листьях Rh. impeditum госсипетин, мирицетин, азалеатин, дигидромирицетин и дигидрокверцетин.

Цель нашего исследования - сравнительное изучение состава и содержания фенольных соединений нативного и гидролизованного экстрактов листьев семи видов рододендронов: Rh. parvifolium и Rh. impeditum (секция Rhododendron подсекция Lapponica), Rh. dauricum, Rh. ledebourii, Rh. sichotense и Rh. mucronulatum (секция Rhododendron подсекция Rhodorastra), R. adamsii (секция Pogonanthum).

\section{Экспериментальная часть}

Состав и содержание флавоноидов в листьях рододендронов, собранных в фазе созревания семян (05.09.2010), определяли в образцах, перенесенных взрослыми растениями из естественных популяций (табл. 1) в дендрарий ЦСБС СО РАН. Таким образом, все особи находились в одних и тех же природноклиматических условиях.

Содержание суммы флавоноидов (в пересчете на рутин) определяли хроматоспектрофотометрическим методом [20, с. 33-34].

Для двумерной хроматографии экстрактов на бумаге использовали системы: $н$-бутанол - уксусная кислота - вода (40:12:28) (БУВ) (первое направление) и $2 \%$ уксусная кислота (второе направление). Оптическую плотность полученных элюатов определяли на спектрофотометре СФ-26 при длине волны 365 нм. Для построения калибровочного графика использовали раствор рутина в $40 \%$ этаноле.

Таблица 1. Происхождение исследованных образцов растений видов рода Rhododendron

\begin{tabular}{|c|c|}
\hline Вид (номер популяции) & Место сбора \\
\hline Rh. adamsii (I) & Якутия, хребет Западный Янги \\
\hline Rh. adamsii (II) & Респ. Тыва, хребет академика Обручева \\
\hline Rh. parvifolium (I) & Амурская обл., хребет Тукурингра \\
\hline Rh. parvifolium (II) & Якутия, Становой хребет \\
\hline Rh. impeditum & Китай, Восточные Гималаи \\
\hline Rh. ledebourii & Респ. Алтай, Чергинский хребет \\
\hline Rh. sichotense & Приморский край, восточные склоны хребта Сихотэ-Алинь \\
\hline Rh. mucronulatum & Приморский край, полуостров Муравьева-Амурского \\
\hline Rh. dauricum & Респ. Бурятия, Байкальский хребет \\
\hline
\end{tabular}


Анализ агликонов проводили методом высокоэффективной жидкостной хроматографии на аналитической ВЭЖХ-системе, состоящей из жидкостного хроматографа «Agilent 1200» с диодноматричным детектором и системы для сбора и обработки хроматографических данных ChemStation. Разделение проводили на колонке Zorbax SB-C18, размером 4,6×150 мм, с диаметром частиц 5 мкм, применив градиентный режим элюирования. Для приготовления стандартных образцов применяли препараты кверцетина и кемпферола производства фирмы «Fluka».

На основе хроматографических данных были рассчитаны коэффициенты парного (РА) и группового сходства (GA) [21, 22] по следующим формулам:

$$
\begin{gathered}
P A, \%=\frac{\text { Количество компонентов, общих в видах } 1 \text { и } 2}{\text { Общее количество компонентов }} \\
G A, \%=\text { Сумма парных коэффициентов вида }+100 \%
\end{gathered}
$$

\section{Обсуждение результатов}

Результаты исследований (рис. 1) свидетельствуют, что содержание флавоноидов в листьях исследованных видов рододендронов составляет от 1 до $3,5 \%$.

Максимальные показатели содержания флавоноидов обнаружены у Rh. ledebourii, R. sichotense и Rh. adamsii (популяция II).

Методом ВЭЖХ в экстрактах листьев изучаемых видов обнаружено 28 соединений, более половины которых по составу и содержанию составляют флавоноиды. Сопоставление времен удерживания пиков веществ на хроматограммах анализируемых образцов с временами удерживания пиков стандартных образцов и УФ-спектрами позволило идентифицировать свободные агликоны: кверцетин, кемпферол, дигидрокверцетин, мирицетин и гликозиды кверцетина - кверцитрин, рутин и гиперозид (табл. 2).

В экстрактах листьев представителей популяций Rh. adamsii в свободном виде обнаружены кверцетин, кемпферол, дигидрокверцетин и мирицетин (в сумме около 1\%), в экстрактах листьев представителей популяций Rh. parvifolium - кверцетин, кемпферол и дигидрокверцетин $(0,2 \%)$. У Rh. ledebourii, Rh. sichotense и Rh. mucronulatum в свободном виде обнаружены кверцетин и дигидрокверцетин $(0,1 \%)$. В экстракте листьев Rh. dauricum найден только кверцетин, у Rh. impeditum - только мирицетин.

Сумма кверцитрина, рутина и гиперозида в экстрактах листьев видов подсекции Rhodorastra составила 0,5\% (Rh. dauricum) - 1,2\% (Rh. ledebourii), в экстрактах листьев Rh. adamsii и Rh. parvifolium - до 0,8 и 0,4\% соответственно. В экстрактах листьев Rh. impeditum указанные гликозиды кверцетина не обнаружены.

Степень парного сходства исследованных видов по составу фенольных соединений экстрактов листьев составила 36-93\% (табл. 3). Максимальное парное сходство обнаружено между популяциями $R h$. parvifolium (93\%), между популяциями Rh. adamsii - значительно ниже (61\%). Относительно высокая степень сходства обнаружена между видами подсекции Rhodorastra (68-79\%), а также в парах Rh. sichotense с Rh. parvifolium I и Rh. adamsii II (71\%). Сходство остальных видов подсекции Rhodorastra с видами из других подсекций значительно ниже (46-64\%). Парное сходство Rh. adamsii с видами из подсекции Rhodorastra (46-71\%) и Rh. parvifolium с видами этой подсекции (43-71\%) сопоставимо с аналогичными величинами между популяциями Rh. adamsii и Rh. parvifolium (54-71\%).

Рис. 1. Содержание флавоноидов (\% от абсолютно сухой массы) в листьях растений видов рода Rhododendron L.

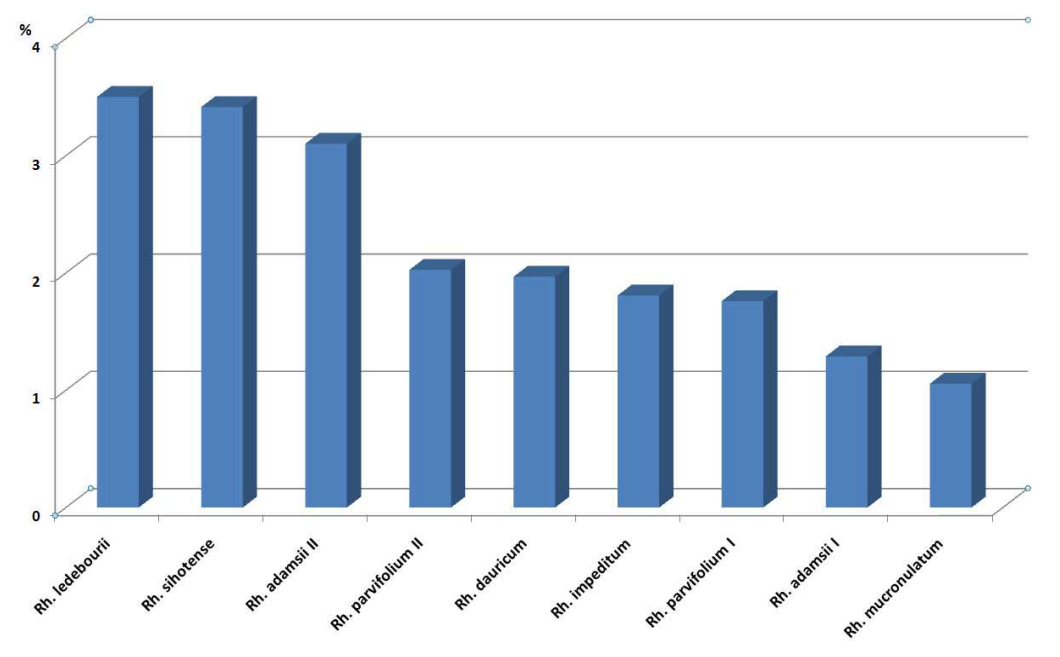


Таблица 2. Содержание свободных агликонов и гликозидов флавоноидов в экстрактах листьев видов рода Rhododendron L. (\% от абсолютно сухой массы)

\begin{tabular}{l|c|c|c|c|c|c|c|c|c}
\hline \multicolumn{1}{c|}{ Вид } & $\mathrm{Q}$ & $\mathrm{K}$ & $\mathrm{M}$ & $\mathrm{dhQ}$ & $\begin{array}{c}\text { Сумма } \\
\text { агликонов }\end{array}$ & Гиперозид & Рутин & Кверцитрин & $\begin{array}{c}\text { Сумма } \\
\text { гликозидов }\end{array}$ \\
\hline Rh. adamsii I & 0,04 & 0,06 & 0,74 & 0,19 & 1,03 & 0,10 & 0,003 & 0,00 & 0,10 \\
Rh. adamsii II & 0,04 & 0,01 & 0,53 & 0,32 & 0,90 & 0,61 & 0,12 & 0,02 & 0,75 \\
Rh. parvifolium I & 0,02 & 0,01 & 0,00 & 0,19 & 0,22 & 0,36 & 0,05 & 0,02 & 0,43 \\
Rh. parvifolium II & 0,12 & 0,05 & 0,00 & 0,00 & 0,17 & 0,22 & 0,04 & 0,03 & 0,29 \\
Rh. impeditum & 0,00 & 0,00 & 0,04 & 0,00 & 0,04 & 0,00 & 0,00 & 0,00 & 0,00 \\
Rh. ledebourii & 0,02 & 0,00 & 0,00 & 0,12 & 0,14 & 0,44 & 0,05 & 0,68 & 1,17 \\
Rh. sichotense & 0,01 & 0,00 & 0,00 & 0,07 & 0,08 & 0,78 & 0,09 & 0,11 & 0,98 \\
Rh. mucronulatum & 0,02 & 0,00 & 0,00 & 0,07 & 0,09 & 0,06 & 0,01 & 0,007 & 0,08 \\
Rh. dauricum & 0,01 & 0,00 & 0,00 & 0,00 & 0,01 & 0,51 & 0,00 & 0,00 & 0,51 \\
\hline
\end{tabular}

Условные обозначения: Q - кверцетин, $\mathrm{K}$ - кемпферол, M - мирицетин, dhQ - дигидрокверцетин.

Таблица 3. Парное и групповое сходство видов Rhododendron по составу флавоноидов экстрактов листьев (\%)

\begin{tabular}{|c|c|c|c|c|c|c|c|c|c|c|}
\hline Виды & 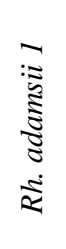 & 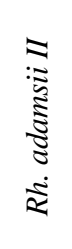 & 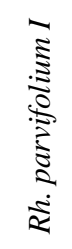 & 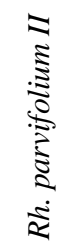 & 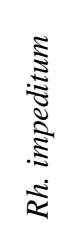 & 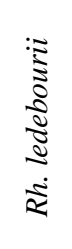 & 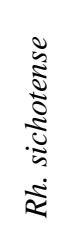 & 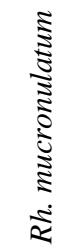 & 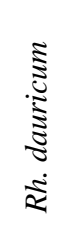 & 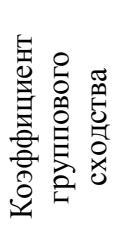 \\
\hline $\begin{array}{l}\text { Rh. adamsii I } \\
\text { Rh. adamsii II } \\
\text { Rh. parvifolium I } \\
\text { Rh. parvifolium II } \\
\text { Rh. impeditum } \\
\text { Rh. ledebourii } \\
\text { Rh. sichotense } \\
\text { Rh. mucronulatum } \\
\text { Rh. dauricum }\end{array}$ & 100 & $\begin{array}{l}60,7 \\
100\end{array}$ & $\begin{array}{l}60,7 \\
71,4 \\
100\end{array}$ & $\begin{array}{c}53,6 \\
64,3 \\
92,9 \\
100\end{array}$ & $\begin{array}{c}46,4 \\
35,7 \\
50,0 \\
57,1 \\
100\end{array}$ & $\begin{array}{c}46,4 \\
64,3 \\
57,1 \\
50,0 \\
42,9 \\
100\end{array}$ & $\begin{array}{c}53,6 \\
71,4 \\
71,4 \\
64,3 \\
42,9 \\
78,6 \\
100\end{array}$ & $\begin{array}{l}46,4 \\
64,3 \\
42,9 \\
42,9 \\
35,7 \\
71,4 \\
71,4 \\
100\end{array}$ & $\begin{array}{l}50,0 \\
53,6 \\
46,4 \\
53,6 \\
57,1 \\
67,9 \\
75,0 \\
75,0 \\
100\end{array}$ & $\begin{array}{l}517,9 \\
585,7 \\
592,9 \\
578,6 \\
467,9 \\
578,6 \\
628,6 \\
550,0 \\
578,6\end{array}$ \\
\hline
\end{tabular}

Вид Rh. impeditum обладает низкой степенью сходства со всеми видами (минимальной - с $R h$. mucronulatum), относительно более высокой - с Rh. parvifolium и представителем подсекции Rhodorastra $R h$. dauricum. Степень группового сходства $R h$. impeditum минимальна. Максимальная степень группового сходства обнаружена у Rh. sichotense.

В гидролизатах листьев изучаемых видов рода Rhododendron обнаружено 12 соединений, которые в соответствии с величинами максимумов УФ-спектров могут быть отнесены к флавоноидам, фенолкарбоновым кислотам и кумаринам [23, 24]. Сопоставление времен удерживания пиков веществ на хроматограммах анализируемых образцов с временами удерживания пиков стандартных образцов и УФ-спектрами позволило идентифицировать пять из них: кверцетин, кемпферол, мирицетин, дигидрокверцетин и коричную кислоту. Агликон XI предварительно идентифицирован как апигенин (табл. 4). Агликоны II и V по спектральным характеристикам предположительно отнесены к флавонолам.

Содержание агликонов флавоноидов у исследованных видов варьирует от 0,3 (Rh. parvifolium II) до более $1 \%$ (Rh. adamsii II, Rh. ledebourii, Rh. sichotense) (табл. 5), в том числе кверцетин - от 0,1 до $0,9 \%$, дигидрокверцетин - от 0,12 до 0,7\%, мирицетин - от 0,006 до 0,15\%, кемпферол - от 0,003 до 0,04\%. Основными агликоновыми компонентами гидролизатов Rh. impeditum является кверцетин, Rh. adamsii, Rh. parvifolium, Rh. ledebourii, Rh. sichotense и Rh. mиcronulatum - кверцетин и дигидрокверцетин, у Rh. dauricum - кверцетин, мирицетин и дигидрокверцетин. Последний вид содержит также в значительном количестве агликон II. В гидролизате Rh. impeditum не обнаружены кемпферол и дигидрокверцетин, при этом выявлено довольно значительное количество агликонов II и XI. Коричная кислота найдена у Rh. adamsii, Rh. parvifolium, Rh. impeditum, Rh. ledebourii, агликон XII - у Rh. sichotense и Rh. mucronulatum, агликон XI - только у Rh. impeditum.

Максимальное содержание кверцетина обнаружено в гидролизате Rh. ledebourii $(0,91 \%)$. Относительно высокое содержание кверцетина $(0,71 \%)$ и дигидрокверцетина $(0,25 \%)$ найдено у Rh. sichotense. Наиболее сбалансированный и полный набор агликонов с максимальным содержанием мирицетина $(0,15 \%)$ и агликона II (0,28\%) отмечен у $R h$. dauricum. Популяция $R h$. parvifolium I выделяется значительным суммарным содержанием агликонов флавоноидов с высоким содержанием дигидрокверцетина $(0,69 \%)$. 
Таблица 4. Хроматографические и спектральные характеристики агликонов гидролизатов растений видов рода Rhododendron

\begin{tabular}{c|c|c|c}
\hline Номер пика & Вещество & Время удерживания, мин & $\lambda_{\max }$, нм \\
\hline 1 & Дигидрокверцетин & 2,5 & 290,360 \\
2 & Агликон II & 2,9 & 270,340 \\
3 & Агликон III & 3,4 & 255,375 \\
4 & Мирицетин & 3,8 & 270,350 \\
5 & Агликон V & 4,6 & 255,340 \\
6 & Агликон VI & 5,2 & 256,370 \\
7 & Кверцетин & 6,6 & 222,274 \\
8 & Коричная кислота & 7,3 & 270,340 \\
9 & Агликон IX & 8,1 & 269,372 \\
10 & Кемпферол & 11,2 & 270,340 \\
11 & Агликон ХІ & 12,9 & 340 \\
12 & Агликон ХІІ & 15,8 & \\
\hline
\end{tabular}

Таблица 5. Содержание агликонов флавоноидов и коричной кислоты в гидролизатах листьев видов рода Rhododendron (\% от абсолютно сухой массы)

\begin{tabular}{l|c|c|c|c|c|c|c|c|c}
\hline \multicolumn{1}{c|}{ Вид } & $\mathrm{Q}$ & $\mathrm{K}$ & $\mathrm{M}$ & $\mathrm{dhQ}$ & $\mathrm{A} \mathrm{II}$ & $\mathrm{A} \mathrm{V}$ & Cin.a. & А ХІ & $\begin{array}{c}\text { Сумма } \\
\text { агликонов }\end{array}$ \\
\hline Rh. adamsii I & 0,36 & 0,04 & 0,06 & 0,40 & 0,00 & 0,00 & 0,05 & 0,00 & 0,91 \\
Rh. adamsii II & 0,71 & 0,04 & 0,03 & 0,26 & 0,003 & 0,00 & 0,07 & 0,00 & 1,11 \\
Rh. parvifolium I & 0,19 & 0,02 & 0,00 & 0,69 & 0,00 & 0,002 & 0,00 & 0,00 & 0,90 \\
Rh. parvifolium II & 0,08 & 0,01 & 0,00 & 0,17 & 0,00 & 0,00 & 0,04 & 0,00 & 0,30 \\
Rh. impeditum & 0,35 & 0,00 & 0,02 & 0,00 & 0,04 & 0,00 & 0,02 & 0,02 & 0,45 \\
Rh. ledebourii & 0,91 & 0,03 & 0,006 & 0,12 & 0,005 & 0,003 & 0,02 & 0,00 & 1,10 \\
Rh. sichotense & 0,71 & 0,03 & 0,00 & 0,25 & 0,01 & 0,007 & 0,00 & 0,00 & 1,00 \\
Rh. mucronulatum & 0,20 & 0,003 & 0,007 & 0,14 & 0,08 & 0,001 & 0,00 & 0,00 & 0,43 \\
Rh. dauricum & 0,29 & 0,008 & 0,15 & 0,16 & 0,28 & 0,04 & 0,00 & 0,00 & 0,93 \\
\hline
\end{tabular}

Условные обозначения: А - агликон, Сin.a. - коричная кислота.

Содержание свободных агликонов в сумме агликонов у Rh. ledebourii, Rh. sichotense и Rh. mucronulatum, Rh. impeditum и популяции Rh. parvifolium I (табл. 2, табл. 5) находится в пределах от 9 до $24 \%$. В популяциях Rh. adamsii и Rh. parvifolium II преобладают агликоны в свободной форме. У вида Rh. dauricum преобладают связанные формы агликонов. Здесь следует отметить, что низкое содержание связанного мирицетина может быть обусловлено нестабильностью мирицетина в процессах гидролиза экстрактов (нами был отмечен факт значительной убыли этого агликона при ВЭЖХ-хроматографировании стандартных растворов).

Диапазон величины парного сходства видов по составу фенольных соединений гидролизатов сопоставим с аналогичными величинами для соединений нативных экстрактов (33-92\%) (табл. 6). Парное сходство популяций видов Rh. parvifolium и Rh. adamsii составляет 83\%. Максимальная степень парного сходства обнаружена между популяциями Rh. adamsii c Rh. ledebourii. Эти виды имеют максимальную степень группового сходства.

Степень сходства между видами подсекции Rhodorastra значительно варьирует (58-92\%). Наибольшее сходство имеет состав флавоноидов пар видов Rh. sichotense - Rh. dauricum (92\%) и Rh. ledebourii-Rh. mucronulatum (83\%). Вид Rh. ledebourii по составу фенольных соединений гидролизатов имеет очень высокое сходство с $R h$. adamsii (92\%), при этом в парах Rh. sichotense - Rh. parvifolium I и Rh. sichotense - Rh. adamsii II его степень также достаточно высока, как и по составу фенольных соединений экстрактов (75 и $67 \%$ соответственно). Парное сходство Rh. adamsii с видами из подсекции Rhodorastra (50-92\%) и Rh. parvifolium с видами этой подсекции (50-83\%) варьирует, а аналогичная величина между популяциями $R h$. adamsii и Rh. parvifolium (75\%) входит в эти диапазоны.

Вид Rh. impeditum имеет очень низкую степень сходства с остальными видами (минимальную - с Rh. sichotense). Однако, в отличие от компонентов экстрактов, по компонентам гидролизатов сходство значительно более высокое: $67 \%$ с Rh. adamsii и 75 \% с Rh. ledebourii. Отличительными признаками этого вида являются отсутствие кемпферола, дигидрокверцетина и присутствие флавонового агликона XI.

С точки зрения современной хемотаксономии агликоновый состав обладает большей стабильностью по сравнению с составом гликозидов, варьирующим в зависимости от объема вида, его ареала, внутривидового полиморфизма, экологической дифференциации, сезона и фазы жизненного цикла индивидуума [20, с. 111-117; 25]. Сравнение по составу гидролизатов является более корректным и более адекватно отражает связи между исследованными образцами. 
Таблица 6. Парное и групповое сходство видов Rhododendron по составу фенольных соединений гидролизатов листьев (\%)

\begin{tabular}{|c|c|c|c|c|c|c|c|c|c|c|}
\hline Виды & 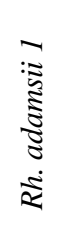 & 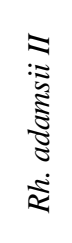 & 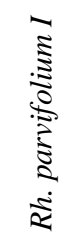 & 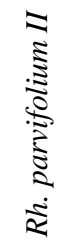 & 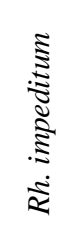 & 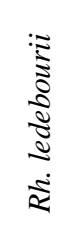 & 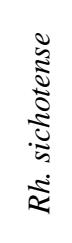 & 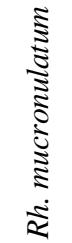 & 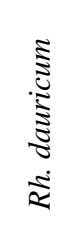 & 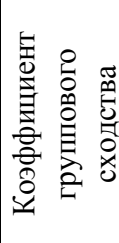 \\
\hline $\begin{array}{l}\text { Rh. adamsii I } \\
\text { Rh. adamsii II } \\
\text { Rh. parvifolium I } \\
\text { Rh. parvifolium II } \\
\text { Rh. impeditum } \\
\text { Rh. ledebourii } \\
\text { Rh. sichotense } \\
\text { Rh. mucronulatum } \\
\text { Rh. dauricum }\end{array}$ & 100 & $\begin{array}{c}83,3 \\
100\end{array}$ & $\begin{array}{c}75,0 \\
75,0 \\
100\end{array}$ & $\begin{array}{r}75,0 \\
75,0 \\
83,3 \\
100\end{array}$ & $\begin{array}{l}66,7 \\
66,7 \\
41,7 \\
41,7 \\
100\end{array}$ & $\begin{array}{l}91,7 \\
91,7 \\
66,7 \\
66,7 \\
75,0 \\
100\end{array}$ & $\begin{array}{c}50,0 \\
66,7 \\
75,0 \\
58,3 \\
33,3 \\
58,3 \\
100\end{array}$ & $\begin{array}{c}75,0 \\
75,0 \\
66,7 \\
50,0 \\
58,3 \\
83,3 \\
75,0 \\
100\end{array}$ & $\begin{array}{r}58,3 \\
75,0 \\
83,3 \\
66,7 \\
41,7 \\
66,7 \\
91,7 \\
66,7 \\
100\end{array}$ & $\begin{array}{l}675,0 \\
708,3 \\
666,7 \\
616,7 \\
525,0 \\
700,0 \\
608,3 \\
650,0 \\
650,0\end{array}$ \\
\hline
\end{tabular}

Гидролизаты растений из двух популяций видов Rh. adamsii и Rh. parvifolium различаются по наличию одного (агликон II) и двух компонентов (коричная кислота и агликон V у Rh. parvifolium) соответственно. Поэтому при сравнении агликоновых профилей видов использованы данные по обеим популяциям (рис. 2).

Виды Rh. adamsii и Rh. ledebourii обладают идентичным и наиболее полным составом агликонов. $R h$. parvifolium и Rh. dauricum содержат только часть этих компонентов, а Rh. impeditum, Rh. sichotense и Rh. mucronulatum имеют в своем составе агликоны XI и XII, не содержащиеся в остальных видах. Другой важной особенностью состава флавоноидов $R h$. impeditum является отсутствие дигидрокверцетина и кемпферола.

Таким образом, по составу флавоноидов $R h$. impeditum наиболее сильно отличается от остальных видов и имеет очень незначительную степень сходства с Rh. parvifolium - другим видом из подсекции Lapponica. Его сходство по составу гидролизатов с Rh. adamsii значительно выше. В подсекции Rhodorastra особенностью видов Rh. sichotense и Rh. тисronulatum является содержание агликона XII, а для Rh. dauricum характерно минимальное количество компонентов.

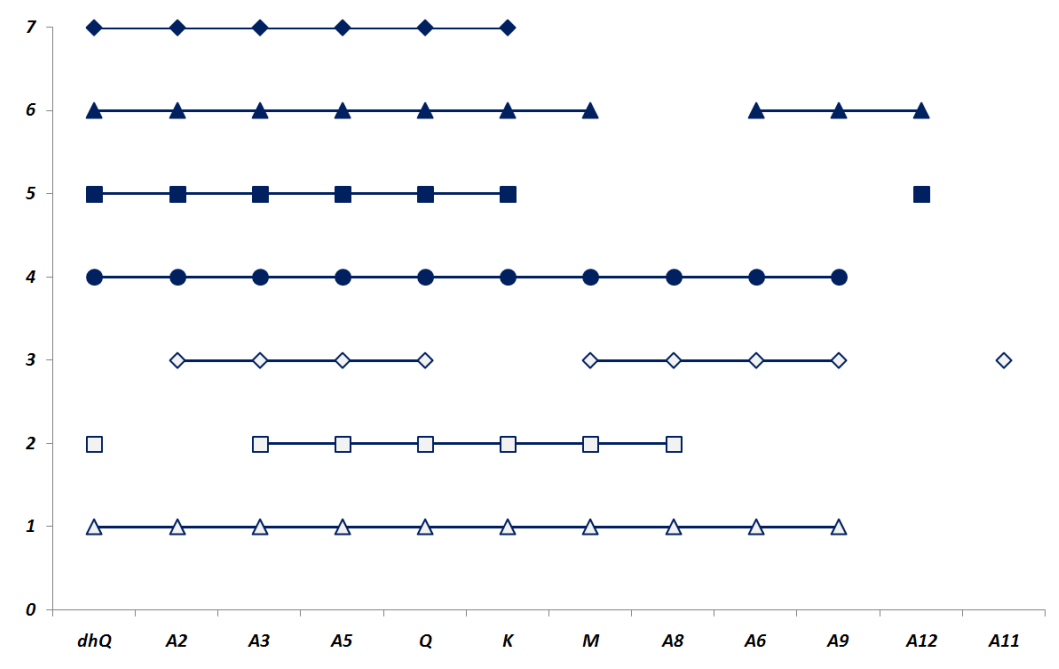

Рис. 2. Схема агликоновых профилей видов рода Rhododendron. Условные обозначения. По оси абсцисс: А2-A11 - агликоны 2-11, $\mathrm{dhQ}$ - дигидрокверцетин, $\mathrm{Q}$ - кверцетин, K - кемпферол, М - мирицетин; по оси ординат: 1 - Rh. adamsii, $2-R h$. parvifolia, 3 - Rh. impeditum, $4-R h$. ledeburii, $5-R h$. sichotense, 6-Rh. mucronulatum, 7 - Rh. dauricum)

\section{Выводы}

1. Содержание агликонов в гидролизатах большинства исследованных видов (кроме Rh. impeditum и Rh. mucronulatum) составляет около $1 \%$. В составе агликонов преобладают кверцетин и дигидрокверцетин.

2. У видов Rh. adamsii и Rh. parvifolium агликоны обнаружены преимущественно в свободном состоянии, а у видов подсекции Rhodorastra - в связанном. 
3. Степень парного сходства исследованных видов по составу фенольных соединений экстрактов и гидролизатов варьирует в пределах от 30 до 90\%. Обнаружена высокая степень сходства по составу гидролизатов пар видов Rh. sichotense - Rh. dauricum и Rh. adamsii - Rh. ledebourii.

4. Анализ сходства состава флавоноидов исследованных видов рода не показал соответствия анатомоморфологической классификации Д. Чемберлена. Выявлена значительная степень родства видов Rh. adamsii и Rh. parvifolium. Минимальная степень группового сходства по составу флавоноидов экстрактов и гидролизатов Rh. impeditum ставит под сомнение его положение, наряду с Rh. parvifolium, в подсекции Lapponica.

5. В подсекции Rhodorastra выявлена довольно значительная степень дифференциации видов.

\section{Список литературы}

1. Белоусов М.В., Саратиков А.С., Ахмеджанов Р.Р., Березовская Т.П., Юсубов М.С., Дмитрук С.Е., Басова Е.В. Биологическая активность видов семейства Ericaceae флоры Сибири и Дальнего Востока // Растительные ресурсы. 2006. Т. 42, № 2. С. 90-101.

2. Усов Л.А., Мирович В.М., Кичигина Е.Л., Левента А.И. К противовоспалительному действию рододендронов Прибайкалья // Сибирский медицинский журнал. 1997. №3. С. 31-32.

3. Harborne J., Williams C. Leaf survey of flavonoids and simple phenols in the genus Rhododendron // Phytochemistry. 1971. Vol. 10, N11. Pp. 2727-2744.

4. Белоусов М.В., Березовская Т.П., Комиссаренко Н.Ф., Тихонова Л.А. Флавоноиды сибирско-дальневосточных видов рододендронов подрода Rhodorastrum // Химия природных соединений. 1998. №4. С. 554-555.

5. Оганесян Э.Т., Бандюкова В.А., Шинкаренко А.Л. Флавонолы Rhododendron luteum и Rh. dauricum // Химия природных соединений. 1967. Т. 3, №4. С. 279.

6. Harborn J.B. Occurrence of flavonol 5-methyl ethers in higher plants and their systematic significance // Phytochemistry. 1969. Vol. 8, N2. Pp. 419-423.

7. Комиссаренко Н.Ф., Левашова И.Г., Шнякина Г.П. Фенольные соединения Rh. dauricum // Химия природных соединений. 1973. Т. 9, №5. С. 665.

8. Костина В.М. Особенности фенольного метаболизма растений рода Rhododendron L. in vivo и in vitro: автореф. дис. ... канд. биол наук. М., 2009. 22 с.

9. Растительные ресурсы России: дикорастущие цветковые растения, их компонентный состав и биологическая активность / отв. ред. А.Л. Буданцев. СПб.; М., 2009. Т. 2. 513 с.

10. Пояркова А.И. Семейство Ericaceae D.К. - вересковые // Флора СССР. М.; Л., 1952. Т. 18. 802 с.

11. Chamberlain D. The genus Rhododendron, its classification and synonymy. Edinburgh, 1996. 181 p.

12. Mingyuan F., Ruizheng F., Mingyou H., Linzhen H., Hanbi Y., Chamberlain D.F. Rhododendron. In: Flora of China. Ed. By W. Zhengyi, P.H. Raven and H. Deyuan. 2005. Vol. 14. Pp. 260-455.

13. Куцев М.Г., Каракулов А.В. Реконструкция филогении рода Rhododendron L. (Ericaceae) флоры России на основе последовательностей спейсеров ITS1-ITS2 // Turczaninowia. 2010. T. 13, №3. С. 59-62.

14. Оленников Д.Н., Танхаева Л.М. Фенольные соединения Rhododendron dauricum байкальского региона // Химия природных соединений. 2010. №3. С. 397-398.

15. Chung T.Y., Kim M.A., Jones A.D. Antioxidative activity of flavonoids isolated from Jindalrae flowers (Rhododendron mucronulatum Turcz.) // Agricultural Chemistry and Biotechnology. 1996. Vol. 39. Pp. 320-326.

16. Lee J.H., Jeon W.J., Yoo E.S., Kim C.M., Kwon Y.S. The chemical constituents and their antioxidant activity of the stem of Rhododendron mucronulatum // Natural Product Sciences. 2005. Vol. 11, N2. Pp. 97-102.

17. Cao Y., Lou C., Fang Y., Ye J. Determination of active ingredients of Rhododendron dauricum L. by capillary electrophoresis with electrochemical detection // Journal of Chromatography A. 2001. Vol. 943. Pp. 153-157.

18. Мирович В.М., Макаренко С.П., Паисова О.И. Изучение химического состава надземных органов рододендрона Адамса методом ВЭЖХ // Бюллетень ВСНЦ СО РАМН. 2005. №7. С. 164-166.

19. Komarova N.I., Rogachev A.D., Chernyak E.I., Morozov S.V., Fomenko V.V., Salakhutdinov N.F. Quantitative HPLC determination of main flavonoid content of Rhododendron adamsii leaves and stems // Chemistry of Natural Compounds. 2009. Vol. 45, N1. Pp. 27-31.

20. Высочина Г.И. Фенольные соединения в систематике и филогении семейства гречишных. Новосибирск, 2004. $240 \mathrm{c}$.

21. Ellison W. L., Alston R.E., Turner B.L. Methods of presentation of crude biochemical data for systematic purposes with particular reference to the genus Bahia (Compositae) // American Journal of Botany. 1962. Vol. 49. Pp. 599-604.

22. Baitha S.N., Pandey V.S. Silica gel chromatographic study of phenolic compounds in some cultivated cucurbits // Himalayan Journal of Sciences. 2003. Vol. 1, N2. Pp. 123-125.

23. Клышев Л.К., Бандюкова В.А., Алюкина Л.С. Флавоноиды растений (распространение, физико-химические свойства, методы исследования). Алма-Ата, 1978. 200 с.

24. Mabry T.J., Markham K.R., Thomas M.B. The systematic identifcation of favonoid. Heidelberg; N.Y., 1970. 631 p.

25. Карпова Е.А., Храмова Е.П., Высочина Г.И. Содержание флавоноидов в некоторых видах рода Euphorbia L. // Химия растительного сырья. 2008. №3. С. 75-81. 
Karpova E.A. , Karakulov A.V. FLAVONOIDS OF SOME RHODODENDRON SPECIES OF FLORA OF SIBERIA AND THE FAR EAST

Central siberian botanical garden Russian academy of sciences Siberian branch, Zolotodolinskaya st., 101,

Novosibirsk, 630090 (Russia),e-mail: karyevg@mail.ru

The composition and content of flavonoids glycosides and aglycones in the leaves of Rhododendron adamsii, Rh. parvifolium, Rh. impeditum, and the closely related species of the subsection Rhodorastra (Rh. dauricum, Rh. ledebourii, Rh. sichotense, Rh. mucronulatum) from populations of the Altai, Yakutia, Tuva, the Amur region and Primorsky Krai, Buryatia, China were studied by HPLC. The aglycones content in hydrolysates of the majority of the species is about $1 \%$, and quercetin and dihydroquercetin prevail in aglycones composition. In Rh. adamsii and Rh. parvifolium aglycones are found predominantly in the free state, and in the species of the subsection Rhodorastra - in a bound one. Values of paired affinity of the investigated species on composition of phenolic compounds of extracts and hydrolysates vary from 30 to $90 \%$, maximums are in pairs $R h$. sichotense-Rh. dauricum, Rh. adamsii-Rh. ledebourii. As a result of the analysis of affinity of flavonoids composition of the species relation with D. Chamberlain's anatomo-morphological classification is not exposed. Significant value of affinity $R h$. adamsii and $R h$. parvifolium is revealed. The minimum value of group affinity on flavonoids composition of extracts and hydrolysates of $R h$. impeditum casts doubt on his position equally with $R h$. parvifolium in the subsection Lapponica.

Keywords: Rhododendron, flavonoids, flavonols, quercetin, kaempferol, myricetin, dihydroquercetin.

\section{References}

1. Belousov M.V., Saratikov A.S., Akhmedzhanov R.R., Berezovskaia T.P., Iusubov M.S., Dmitruk S.E., Basova E.V. Rastitel'nye resursy, 2006, vol. 42, no. 2, pp. 90-101. (in Russ.).

2. Usov L.A., Mirovich V.M., Kichigina E.L., Leventa A.I. Sibirskii meditsinskii zhurnal, 1997, no. 3, pp. 31-32. (in Russ.).

3. Harborne J., Williams C. Phytochemistry, 1971, vol. 10, no. 11, pp. 2727-2744.

4. Belousov M.V., Berezovskaia T.P., Komissarenko N.F., Tikhonova L.A. Khimiia prirodnykh soedinenii, 1998, no. 4, pp. 554-555. (in Russ.).

5. Oganesian E.T., Bandiukova V.A., Shinkarenko A.L. Khimiia prirodnykh soedinenii, 1967, vol. 3, no. 4, p. 279. (in Russ.).

6. Harborn J.B. Phytochemistry, 1969, vol. 8, no. 2, pp. 419-423.

7. Komissarenko N.F., Levashova I.G., Shniakina G.P. Khimiia prirodnykh soedinenii, 1973, vol. 9, no. 5, p. 665. (in Russ.).

8. Kostina V.M. Osobennosti fenol'nogo metabolizma rastenii roda Rhododendron L. in vivo i in vitro: avto-ref. dis. ... kand. biol nauk. [Features phenolic metabolism of plants of the genus Rhododendron L. in vivo and in vitro: author's Candidate of Biological Sciences.]. Moscow, 2009, 22 p. (in Russ.).

9. Rastitel'nye resursy Rossii: dikorastushchie tsvetkovye rasteniia, ikh komponentnyi sostav i biologicheskaia aktivnost' / T. 2. Otv. red. A.L. Budantsev. [Plant Resources of Russia: wild flowering plants, their component structure and biological activity. Ed. A.L. Budantsev]. St Petersburg, Moscow, 2009, Vol. 2. 513 p. (in Russ.).

10. Flora SSSR. [Flora of the USSR.]. Moscow; Leningrad, 1952, vol. 18, 802 p. (in Russ.).

11. Chamberlain D. The genus Rhododendron, its classification and synonymy. Edinburgh, 1996. 181 p.

12. Mingyuan F., Ruizheng F., Mingyou H., Linzhen H., Hanbi Y., Chamberlain D.F. Rhododendron. In: Flora of China. Ed. By W. Zhengyi, P.H. Raven and H. Deyuan. 2005, vol. 14, pp. 260-455.

13. Kutsev M.G., Karakulov A.V. Turczaninowia, 2010, vol. 13, no. 3, pp. 59-62. (in Russ.).

14. Olennikov D.N., Tankhaeva L.M. Khimiia prirodnykh soedinenii, 2010, no. 3, pp. 397-398. (in Russ.).

15. Chung T.Y., Kim M.A., Jones A.D. Agricultural Chemistry and Biotechnology, 1996, vol. 39, pp. 320-326.

16. Lee J.H., Jeon W.J., Yoo E.S., Kim C.M., Kwon Y.S. Natural Product Sciences, 2005, vol. 11, no. 2, pp. $97-102$.

17. Cao Y., Lou C., Fang Y., Ye J. Journal of Chromatography A, 2001, vol. 943, pp. 153-157.

18. Mirovich V.M., Makarenko S.P., Paisova O.I. Biulleten' VSNTs SO RAMN, 2005, no. 7, pp. 164-166. (in Russ.).

19. Komarova N.I., Rogachev A.D., Chernyak E.I., Morozov S.V., Fomenko V.V., Salakhutdinov N.F. Chemistry of Natural Compounds, 2009, vol. 45, no. 1, pp. 27-31.

20. Vysochina G.I. Fenol'nye soedineniia v sistematike $i$ filogenii semeistva grechishnykh. [Phenolic compounds in the taxonomy and phylogeny of the family Polygonaceae.]. Novosibirsk, 2004, 240 p. (in Russ.).

21. Ellison W. L., Alston R.E., Turner B.L. American Journal of Botany, 1962, vol. 49, pp. 599-604.

22. Baitha S.N., Pandey V.S. Himalayan Journal of Sciences, 2003, vol. 1, no. 2, pp. 123-125.

23. Klyshev L.K., Bandiukova V.A., Aliukina L.S. Flavonoidy rastenii (rasprostranenie, fiziko-khimicheskie svoistva, metody issledovaniia). [Flavonoids are plant (distribution, physical and chemical properties, methods of study)]. Alma-Ata, 1978, 200 p. (in Russ.).

24. Mabry T.J., Markham K.R., Thomas M.B. The systematic identifcation of favonoid. Heidelberg; N.Y., 1970, 631 p.

25. Karpova E.A., Khramova E.P., Vysochina G.I. Khimiia rastitel'nogo syr'ia, 2008, no. 3, pp. 75-81. (in Russ.).

\footnotetext{
* Corresponding author.
} 